\title{
DIREITOS HUMANOS, O FUNCIONALISMO POLÍTICO E O MINIMALISMO JURÍDICO EM JOHN RAWLS E JOSEPH RAZ
}

\author{
HUMAN RIGHTS, POLITICAL FUNCTIONALISM AND LEGAL MINIMALISM IN JOHN RAWLS AND \\ JOSEPH RAZ
}

Rodolfo de Freitas Jacarandá ${ }^{1}$

\begin{abstract}
Resumo: As teorias tradicionais de direitos humanos - teorias normativas e substantivas - estabelecem critérios gerais para que valores morais possam ser normativamente universalizados, além dos motivos para que sejam impostas obrigações para seu cumprimento. Nas últimas décadas, contudo, filósofos e teóricos do direito, preocupados com o realismo global do discurso de aplicação dos direitos humanos, a maioria deles sob a influência do trabalho de John Rawls, criticaram as teorias tradicionais a partir de uma análise funcionalista dos direitos humanos. Colocando as práticas jurídicas e políticas em maior evidência, os funcionalistas políticos como Charles Beitz e Joseph Raz argumentam a falta de precisão lógica e a incoerência na proliferação excessiva de direitos atribuída às abordagens normativas e substantivas de teóricos como Jeremy Waldron e James Griffin. Neste artigo vou descrever os principais argumentos do funcionalismo político em direitos humanos, enfatizando o minimalismo jurídico comum a essa abordagem. Meu objetivo é avaliar as condições de aplicação da teoria aos problemas decorrentes da falta de uma coerente fundamentação teórica atribuída, pelos funcionalistas, aos pensadores mais ortodoxos. Minhas conclusões demonstram que sem haver maior integração entre os grupos teóricos continua muito difícil compreender corretamente a complexidade dos desafios da teoria e da prática cotidiana em direitos humanos.
\end{abstract}

Palavras-chave: Direitos humanos. Funcionalismo político. Minimalismo jurídico. Teorias tradicionais.

\begin{abstract}
Traditional human rights theories - normative and substantive theories - establish general criteria for moral values to be normatively universalized, as well as the reasons for imposing obligations for compliance. In recent decades, however, philosophers and legal theorists, concerned with the global realism of human rights discourse, most of them under the influence of John Rawls's work, have criticized traditional theories based on a functionalist account of human rights. Putting political and legal practices in evidence, political functionalists like Charles Beitz and Joseph Raz argue for the lack of logical precision and the incoherence in the excessive proliferation of rights attributed to the normative and substantive approaches of such authors as Jeremy Waldron and James Griffin. In this paper I will describe the main arguments of the political functionalism account in human rights, emphasizing the legal minimalism common to this approach. My objective is to evaluate the conditions of application of the theory to the problems arising from the lack of a coherent theoretical foundation attributed by the functionalists to the more orthodox thinkers. My conclusions demonstrate that without greater integration between the theoretical groups it remains very difficult to correctly understand the complexity of the challenges of theory and everyday human rights practice.
\end{abstract}

Keywords: Human rights. Political functionalism. Legal minimalism. Traditional theories.

Recebido em 18 de janeiro de 2018 Avaliado em 30 de outubro de 2020 (AVALIADOR A) Avaliado em 5 de abril de 2021 (AVALIADOR B) Aceito em 8 de abril de 2021

\footnotetext{
1 Doutor em Filosofia pela Universidade Estadual de Campinas; Mestre em Filosofia pela Pontifícia Universidade Católica de Campinas; Professor Associado do Departamento de Filosofia da Universidade Federal de Rondônia; https://orcid. org/0000-0002-2047-1403; rfjacaranda@uol.com.br
} 


\section{Introdução}

Quão importante é para a práxis cotidiana o esforço das teorias tradicionais de resolver o problema da falta de uma fundamentação filosófica coerente e bem justificada para os direitos humanos? Para filósofos do direito como Joseph Raz (2013, p. 7) a resposta é: "amplamente irrelevante".

Opiniões de pensadores funcionalistas como Raz, dirigidas contra teóricos do direito como Jeremy Waldron (2013, 2015) e James Griffin (2008, 2010a, 2010b), intensificaram as discussões sobre a fundamentação dos direitos humanos nos últimos anos (BESSON, TASIOULAS, 2010; CRUFT; LIAO; RENZO, 2015; DONNELLY, 2003; FREEMAN, 2010). Esses debates, opondo fundacionalistas mais ou menos tradicionais e funcionalistas políticos preocupados com a pragmática jurídica das relações internacionais, revelam a complexidade dos problemas que ainda cercam a natureza e a efetivação dos direitos humanos em escala global.

O discurso dos direitos humanos ressurgiu no cenário internacional após a segunda guerra mundial a partir de demandas práticas muito bem definidas. A urgência dessas demandas orientou as pesquisas filosóficas conduzidas pelo jovem filósofo francês Jacques Havet e pelo britânico Julien Huxley, da UNESCO, para a Comissão de Direitos Humanos da ONU, com a finalidade de estabelecer o texto base para a Declaração Universal dos Direitos Humanos (DUDH), de 1948 (GLENDON, 2001; GOODALE, 2017). Mas, como Jacques Maritain deixou claro na época, apesar de ser necessário encontrar fundamentos racionais para validar os direitos humanos, somente foi possível chegar a um texto comum entre "campeões de ideologias violentamente opostas" ignorando essa necessidade, "sob a condição de que ninguém perguntasse pelos porquês." (UNESCO, 1948, p. 1). Algumas décadas depois, a falta de coerência entre esses porquês cobrou seu preço diante da necessidade de aplicação das normas de direitos humanos em ambientes e conflitos cuja complexidade exorbitaram as expectativas que orientaram os estudos da comissão da Seção de Filosofia e Humanística de Havet e Huxley.

Atualmente, em sua maioria, juristas e filósofos discordam pouco sobre a importância civilizatória que a linguagem dos direitos humanos adquiriu com o fim da guerra fria. No entanto, as discordâncias se acentuam quando se trata de saber se os direitos humanos são direitos morais ou normas jurídicas; se existe alguma racionalidade intrínseca à definição desses direitos ou se ela depende de acordos políticos; se a universalidade é caraterística essencial desses direitos; se é possível abrir mão da universalidade em nome de complexidades culturais locais; se esses direitos devem expressar conteúdos particulares ou se devem informar critérios abstratos gerais que possam conduzir reformas e compromissos entre povos e Estados e assim por diante.

Com a finalidade de expor de forma mais compreensiva os elementos contemporâneos dessa discussão, utilizando uma metodologia analítico-comparativa, vou descrever os argumentos dos principais pensadores funcionalistas contemporâneos, críticos das teorias ortodoxas ou clássicas 
do direito e dos direitos humanos, para quem é preciso abandonar as fontes do direito utilizadas desde as pesquisas que deram origem à DUDH, com o objetivo de tornar esses direitos mais efetivos. Para isso, farei uma breve revisão da teoria dos direitos humanos de John Rawls, principal influência do pensamento funcionalista político em direitos humanos, ainda hoje (1). A seguir, vou descrever e questionar as teorias funcionalistas de Ronald Dworkin e Charles Beitz (2) para, na sequência, apresentar os argumentos antifundacionalistas de Joseph Raz para os direitos humanos na atualidade (3). Minhas conclusões opõem os termos do debate entre Raz e Jeremy Waldron, e apontam a direção de uma necessária integração entre teorias normativas e as teorias políticas de modo a diminuir as incoerências ainda amplamente situadas entre o discurso de justificação e o discurso de aplicação dos direitos humanos.

\section{A reconstrução política dos direitos humanos e o minimalismo jurídico em John Rawls}

Em $O$ direito dos povos (DP) John Rawls (2001) constrói uma fundamentação filosófica dos direitos humanos a partir de uma visão da justiça internacional baseada no direito dos povos - termo utilizado em oposição à palavra estado.

Inicialmente, Rawls (2001, p. 47-48) reformula a noção de posição original de Uma teoria da Justiça e reconsidera a proposta para uma justiça universalizável tendo em vista uma sociedade global dos povos, com base em oito princípios tradicionais de justiça válidos para povos livres e democráticos - um deles, o sexto, é a obediência aos direitos humanos. Mas, em $O$ direito dos povos Rawls insere um novo elemento na teoria para que ela possa ser realisticamente internacionalizada: a posição original, nesse caso, deve admitir a possibilidade de aceitar povos não liberais, embora decentes (RAWLS, 2001, p. 82). Rawls explica que existem cinco tipos de sociedades nacionais: povos liberais; povos decentes; Estados fora da lei; sociedades oneradas por condições desfavoráveis; e absolutismos benevolentes (RAWLS, 2001, p. 82-83). Somente para os dois primeiros tipos de sociedades os direitos humanos são exigíveis.

Rawls manifesta preocupação com a necessidade de os povos liberais aceitarem a convivência normativa com outros povos e sociedades cuja organização política não obedeça, necessariamente, ao mesmo modelo de organização de uma democracia liberal. Por isso, ele propõe que uma concepção pluralista razoável da justiça em plano internacional deve incluir uma concepção de tolerância (item 7.2) para com a sociedades que ele define como sociedades hierárquicas decentes (item 8.1). As sociedades hierárquicas decentes são, na forma, comunidades associativas e possuem uma "hierarquia de consulta decente" por meio da qual seus membros, os quais pertencem a grupos diferentes entre si, são representados normativamente na vida pública, cada um deles por um sistema próprio de consulta, determinado por suas regras morais ou tradicionais internas. Contrariando o individualismo normativo de Uma teoria da Justiça, em favor do reconhecimento do povo como unidade moral e de interesses coletivos (POGGE, 2006, p. 211), Rawls (2001, p. 79-80) 
afirma que nessas sociedades decentes os membros possuem, em algum grau, o direito de serem consultados sobre as decisões políticas e é permitido certo nível de dissidência política, mediado pelo poder judiciário, embora nelas sejam permitidas desigualdades básicas e seja negado o direito de igual liberdade para todos os membros (CLARK, 2012, p. 643).

Definir essas sociedades é complexo pois, como bem observa Thomas Pogge (2006, p. 211), não fica claro no texto quais grupos Rawls considera exatamente um "povo", nem se uma pessoa pode pertencer a mais de um povo no mesmo território, por exemplo. Seja como for, os povos liberais devem tolerar tais sociedades decentes porque não podem esperar que todos os povos sejam liberais e porque não devem admitir que possuem o direito de intervir, sem razões fortes como justificativa, na realidade de povos que não negam os direitos humanos (RAWLS, 2001, p. 79). Tolerar e conviver com esses povos pode induzi-los ao liberalismo, afirma Rawls (2001, p. 78), já que não se deve supor que tais sociedades não sofram mudanças graduais, nem que não sejam capazes de se reformar à sua própria maneira. O respeito à boa-fé dessas sociedades nas relações internacionais pode encorajar a mudança que pode elevá-las ao patamar de sociedades liberais (RAWLS, 2001, p. 80).

Para a aceitação definitiva de sociedades decentes no direito dos povos, contudo, Rawls exige dois critérios: o primeiro, que elas sejam pacíficas e procurem atingir seus objetivos externos pela via diplomática; o segundo é subdividido em três partes, sendo a segunda parte a aceitação por todos os membros, em seu território, de obrigações e deveres morais; e a terceira parte é reconhecimento de que a lei deve ser "guiada por uma ideia de justiça do bem comum", e não apenas imposta pela força (RAWLS, 2001, p. 86-87). A primeira parte do segundo critério, enfim, impõe a necessidade de respeitar os direitos humanos.

Nesse ponto, Rawls especifica quais direitos compreende por direitos humanos como base do compromisso para integração de uma sociedade dos povos: o direito à vida (o que inclui o direito aos meios de subsistência e de segurança); à liberdade (contra a escravidão, e à liberdade de consciência); à propriedade; à igualdade formal (como expressa pelas regras da justiça natural, casos similares sendo tratados de forma similar). Após expor sua lista mínima de direitos humanos, Rawls (2001, p. 103) desenvolve então sua visão particular dos direitos humanos, afirmando que eles são uma classe especial de direitos que "restringem as razões justificadoras para a guerra" e colocam "limites à autonomia interna de um regime". Por fim, essa subclasse de direitos deve cumprir três papeis: servir de condição necessária da decência das instituições políticas e da ordem jurídica; seu cumprimento exclui intervenções injustificadas; estabelecer um limite para o pluralismo entre os povos (RAWLS, 2001, p. 105).

Essa lista bastante limitada de direitos associada a algumas poucas funções políticas e jurídicas atraiu muitas críticas para a teoria exposta em $O$ Direito dos povos, sobretudo porque parece bastante incoerente correlacionar os direitos fundamentais necessários para construir uma sociedade justa de povos bem-ordenados - princípios da igualdade de liberdades, igualdade de oportunidades, da diferença e etc. - de Uma teoria da justiça com o que se assemelha ao alto preço a pagar para 
produzir uma teoria da justiça globalizada que obedeça às diretrizes do realismo internacionalista (MACLEOD, 2006, p. 136). Uma crítica bastante forte sustentada por Langlois (2003), Shue (1996) e Voice (2011) alega, por exemplo, que sem direitos amplos de participação política não é possível garantir que governos fortemente hierarquizados cumpram os direitos humanos. Outra objeção à fundamentação de Rawls avança sobre o sentido do minimalismo jurídico de suas proposições, medida que reduz o escopo das normas de direitos humanos e subjuga a importância de numerosos grupos de direitos, sobretudo os direitos econômicos, sociais e culturais (COHEN, 2004; NICKEL, 2006; TASIOULAS, 2002).

Para Alasdair Macleod há duas formas de minimalismo em direitos humanos: o minimalismo justificativo (justificatory minimalism) e o minimalismo de execução (enforcement minimalism). O minimalismo justificativo defende o reconhecimento de poucos direitos como direitos humanos por sustentar que não é possível justificar racionalmente mais do que um número limitado de direitos que se pretenda universalizar, sem incorrer na incoerência ou na profusão ilimitada e irracional de direitos irrealizáveis. O minimalismo de execução se preocupa com a capacidade para colocar em prática os direitos humanos de tal modo que propõe a concentração do potencial para a realização desses direitos em um número conciso e limitado deles, evitando a dispersão de esforços e, portanto, a ineficácia (MACLEOD, 2006, p. 134). Para Macleod a teoria dos direitos humanos de Rawls apela para uma espécie de minimalismo de execução pragmático, traindo o espírito principialista e justificacionista de Uma teoria da Justiça (MACLEOD, 2006, p. 137). Na análise de Macleod, Rawls (2006, p. 137) demonstra em $O$ direito dos povos acentuada má vontade para reconhecer importantes direitos fundamentais como direitos humanos (como nos casos de iguais liberdades e direitos de participação política), ao mesmo tempo em que desvia toda a atenção para um projeto viável de integração que reduz, ao máximo, as hipóteses de intervenções indevidas em nome dos direitos humanos. Esse tipo de preocupação demonstrada por Rawls, contudo, é muito comum e repercute em análises bastante influentes sobre o tema, como aquela expressa por Michael Ignatieff nas Tanner Lectures em 2000:

If human rights principles exist to validate individual agency and collective rights of selfdetermination, then human rights practice is obliged to seek consent for its norms and to abstain from interference when consent is not freely given. Only in strictly defined cases of necessity - where human life is at risk - can coercive human rights interventions be justified. (IGNATIEFF, 2000, p. 298).

Macleod (2006, p. 147) argumenta que sustentar esse tipo de minimalismo para evitar intervenções indevidas parece aceitável e cabível diante de alguns dos parâmetros morais da teoria, mas em sua visão Rawls falha ao sacrificar um elevado número de direitos - e direitos essenciais - sem considerar que na práxis internacional nunca foram muitas as hipóteses de intervenção (sobretudo militar) por violações de direitos humanos e que existem muitas outras ferramentas 
para fomentar o cumprimento dos direitos humanos, sem incorrer no risco da destituição injusta da autodeterminação dos povos.

Kenneth Baynes, argumentando na mesma direção que Ignatieff e também favorável ao minimalismo de Rawls chamou essa abordagem de "mínimo denominador comum" (lowest commom denominator approach), a qual sobrepõe a necessidade de obter consenso nas arenas internacionais à própria preocupação de evitar o discurso intervencionista (BAYNES, 2009, p. 376). Por essa via, os direitos humanos seriam o efeito de um compromisso político razoável e possível entre estados e nações, e tal compromisso somente poderia ser obtido dentro de parâmetros realistas que permitissem a expressão em normas universais de conteúdos originários de tradições variadas, ou seja, esses conteúdos inevitavelmente seriam poucos.

Essa visão dos direitos humanos preocupada com a possibilidade de criar uma associação de povos a mais inclusiva possível - mesmo que admitindo, internacionalmente, acordos inadmissíveis domesticamente -, vinculada às expectativas de eficácia normativa e submetida ao crivo de representantes soberanos (ou autodeterminados) deu origem a todo um campo de estudos que ficou conhecido como funcionalismo político em direitos humanos. Pesquisadores como Charles Beitz (2009), Dworkin (2014), Ignatieff (2000) ou Joseph Raz (2010a, 2010b, 2013) se dedicaram, ou ainda se dedicam, a aprimorar as reflexões de Rawls, defendendo que os direitos humanos não devem ser fundamentados em princípios abstratos de racionalidade moral, nem em um conjunto extenso de valores, naturais ou tradicionais - como o fazem fundacionalistas mais tradicionais como Alan Gewirth (1981, 1982, 1987), James Griffin (2008, 2010a, 2010b) ou Jeremy Waldron (2013, 2015).

Para os pensadores funcionalistas a universalidade dos direitos humanos depende mais de sua capacidade de oferecerem soluções concretas para as maiores ameaças à humanidade do que das tentativas de justificação moral ou do peso qualquer que se possa atribuir, teoricamente, a determinado bem ou valor como sendo mais ou menos essencial para caracterizar a sua existência (DONNELLY, 2007, p. 292).

Existem duas maneiras de caracterizar o funcionalismo contemporâneo, ambas inspiradas em Rawls: as normas de direitos humanos procuram estabelecer condições para o funcionamento legítimo do poder político (Dworkin, Beitz); e os direitos humanos somente podem ser considerados como tais se, e somente, suas violações forem o bastante para derrogar a soberania de um Estado (Ignatieff, Raz) (TASIOULAS, 2012, p. 26). Na próxima seção vou analisar os argumentos dos funcionalistas políticos do primeiro tipo, para, a seguir, avaliar mais detidamente o trabalho de Joseph Raz.

\section{A função legitimadora dos direitos humanos em Ronald Dworkin e Charles Beitz}

Em sua última obra, Justice for Hedgehogs, Ronald Dworkin (2014) esboça uma fundamentação funcionalista dos direitos humanos caracterizando-os como um subgrupo dos 
direitos políticos, responsáveis por fundamentar a legitimidade do exercício do poder governamental. Para Dworkin os direitos humanos são direitos que conferem aos indivíduos "trunfos" para exigirem a adoção por parte do governo de práticas que respeitem a dignidade de todos os membros da comunidade política. A destituição ou a grave ofensa contra esses "trunfos" autoriza a imposição de sérias consequências contra a autonomia do governo, tais como a intervenção humanitária ou mesmo a revolução.

A posição de Dworkin é francamente contrária às teorias normativas clássicas e às teorias substantivas que elevam certos valores à categoria central de fundamento para os direitos humanos - medida que ele considera arbitrária, especialmente no caso de James Griffin (2008), contra quem ele argumenta que defender a personalidade (personhood) e a capacidade do agir normativo (normative agency) como fundamento para os direitos humanos é algo incerto e impreciso (DWORKIN, 2014, p. 698).

A argumentação de Dworkin considera os avanços na legislação internacional de direitos humanos e não reconhece como um problema grave a extensão de direitos das normas e declarações internacionais, nem mesmo os déficits de eficácia que ameaçam solapar a confiança nessas normas. Para ele, a ampla gama de direitos do conjunto normativo internacional de direitos humanos serve de inspiração para que organizações civis ou mesmo estatais continuem lutando para implantar mudanças em suas ordens jurídicas internas (DWORKIN, 2014, p. 510). A carência, contudo, de precisão para definir os direitos humanos deve ser suprida por uma sequência de três operações que descrevo a seguir.

Primeiro, é preciso reconhecer que nem todos os países ou comunidades irão interpretar e aplicar o direito do mesmo modo, assimilando da mesma forma os conteúdos expressos nas normas internacionais. Pode ser o caso, por exemplo, de um Estado defender a liberdade de participação política pelo voto, mas não permitir a criação livre de novos partidos. Ou seja, em direitos humanos não se trata de assumir regras cuja prescrição seja igualmente aplicável em todo lugar (DWORKIN, 2014, p. 511-512), não sendo possível, desse modo, universalizar o compromisso com certa forma específica de efetividade prática desses direitos.

Em segundo lugar, as discordâncias com relação à justiça das práticas que dão efetividade aos direitos políticos devem ser sanadas avaliando se essas práticas respeitam o direito de os seres humanos serem tratados com a dignidade que define a sua natureza. Variações de interpretação para a aplicação prática correta do direito político à igual consideração e respeito são admissíveis, desde que se possa afirmar que o direito mais básico em jogo - o direito abstrato a uma atitude digna - foi garantido. Como diz o próprio Dworkin (2014, p. 512), "pode acontecer de um governo respeitar esse direito básico mesmo quando não alcança um entendimento mais correto dos direitos políticos mais concretos", estabelecendo, por exemplo, um sistema eleitoral, previdenciário ou tributário injusto ou imperfeito, aos olhos de outros Estados mais avançados. $\bigcirc$ que não é o caso quando, por exemplo, 
um programa político exclui do voto certo grupo étnico minoritário em detrimento da participação de todos os outros - ferindo, assim, aquele direito abstrato ao igual tratamento digno.

E em terceiro lugar, somente pode ser considerado direito humano esse direito mais abstrato e mais básico, cujo definição deve proteger os dois princípios da dignidade estabelecidos por Dworkin (2014, p. 512-513): que cada pessoa seja tratada como igual e objetivamente importante em sua comunidade; que cada um possa ter a responsabilidade pessoal de definir o sucesso em sua própria vida.

Assim, a teoria dos direitos humanos de Dworkin encontra sua formulação completa na necessidade de proteger a dignidade dos cidadãos, dentro de uma escala plausível de atuações de boafé de governos interessados em conferir eficácia a essas normas.

Dworkin (2014, p. 493) associa esse limite imposto pelos direitos humanos à definição da própria legitimidade do exercício do poder político, admitindo que nem sempre um governo, que aceita os direitos humanos, consegue evitar, em parte, a negação dos princípios que eles representam - excluindo, por exemplo, uma minoria dos benefícios sociais ou impondo regras um tanto abusivas de comportamento sexual. Mas ao definir a legitimidade como uma questão de graus, seu argumento faz lembrar o apelo de Rawls para sustentar o ingresso na sociedade dos povos de povos hierárquicos de consulta decentes, mas não liberais. Ou seja, na visão de Dworkin os governos podem até cometer erros graves na condução do poder contra a sociedade, mas não podem ferir os direitos humanos, porque isso inviabiliza a legitimidade, autorizando a desobediência civil e até a revolução (DWORKIN, 2014, p. 494).

Charles Beitz (2009) também é um defensor de uma concepção funcionalista dos direitos humanos, construída a partir do suporte argumentativo de natureza prática apresentado por Rawls em $O$ direito dos povos. A grande vantagem da teoria de Rawls, de acordo com Beitz (2009, p. 98), foi abandonar o naturalismo e o normativismo abstrato para se dedicar a investigar a doutrina e a prática dos direitos humanos como ela é encontrada na vida política internacional. Não há, argumenta Beitz, afirmações de prioridade, ponto de partida independente da realidade ou direitos fundamentais que possam ser escolhidos como direitos humanos deixando de lado a importância do discurso normativo como aplicado nas instituições internacionais. Teorias naturalistas ou convencionalistas, afirma Beitz (2009, p. 101), tratam a questão da autoridade dos direitos humanos como algo interno à questão de sua natureza, ou seja, por essa via, entendendo o que são os direitos humanos se poderia determinar o conteúdo de sua doutrina e os motivos para escolhê-los. Por outro lado, uma concepção prática dos direitos humanos abre mão de qualquer visão filosófica sobre a natureza ou a base dos direitos humanos, separando o conceito da compreensão de sua autoridade.

Beitz (2009, p. 102-103) afirma que ao conhecermos as funções exercidas pelos direitos humanos na práxis internacional podemos entender que eles são o nome de um empreendimento político coletivo com propósitos e modos de ação muito peculiares, exercendo a função reguladora do desenvolvimento da organização política e jurídica dos Estados para proteger as pessoas comuns 
contra excessos e abusos graves. Sem entrar no mérito com relação a propor uma lista específica de direitos, a ênfase da reflexão de Beitz recai sobre o termômetro estabelecido pela sociedade de Estados para impor os limites entre o que é ou não aceitável para a convivência pacífica entre esses membros.

A partir dessa abordagem política, seguindo os passos de Rawls, para quem os direitos humanos são padrões de civilização cuja satisfação garante uma sociedade contra intervenções externas e são também um requisito para aceitação na sociedade dos povos, Beitz (2009, p. 128) define os direitos humanos como "padrões para instituições domésticas cuja satisfação é um assunto de interesse internacional." Beitz não demonstra muito interesse em se aventurar pela descrição de quais direitos são direitos humanos - tornando sua posição ainda mais funcionalista do que a de Dworkin, ou seja, a definição do subgrupo dos direitos humanos depende da urgência estabelecida por uma comunidade internacional atenta aos padrões de civilidade que ela mesma define e pretende defender.

Ainda na esteira de Rawls, Beitz (2009, p. 141) argumenta contra o minimalismo, afirmando que essa não é uma decorrência necessária do funcionalismo político. Como o próprio Rawls propôs, os direitos humanos são um subgrupo dos direitos que devem servir como condição para a realização de uma justiça social em sociedades livres e decentes. "A composição específica desse subgrupo", afirma Beitz (2009, p. 144), "é uma questão separada da teoria política global, a ser definida de uma forma que avalie o papel especial que os direitos humanos assumiram no discurso normativo da política mundial."

Apesar dessa negativa, Beitz (2013) conclui que os direitos humanos fazem parte de uma iniciativa global para proteger indivíduos contra ameaças aos seus interesses mais importantes provindas de atos omissivos ou comissivos por parte de seus governantes. $\bigcirc$ que a prática propõe para atingir esse objetivo é tornar relevante e mesmo transformar em preocupação internacional tais aspectos da conduta doméstica (BEITZ, 2009, p. 197).

\section{Direitos humanos e soberania em Joseph Raz}

Para o filósofo Joseph Raz (2010b, p. 47), os direitos humanos passaram a exercer um papel de alto relevo na ordem global após o fim da guerra fria, fazendo com que a própria linguagem dos direitos fosse utilizada com frequência muito maior nas relações internacionais, destacando três objetivos principais: defender o valor de todos os seres humanos, independentemente de sua origem; priorizar agendas políticas não-estatais ou não corporativas; e fortalecer a luta de indivíduos e associações voluntárias, criando canais políticos adicionais capazes de exercer influência e afetar a ordem internacional. Para Raz, contudo, a forma tradicional pela qual o discurso dos direitos humanos foi imposto na agenda global deu origem a um tipo de ativismo que prioriza o valor do 
direito para seus portadores (right-holder), esquecendo a necessidade de estabelecer deveres para os atores (duty-bearers) que serão os responsáveis por garantir que tais direitos sejam respeitados.

Essa desobediência ao que Raz define como um elemento primordial da própria teoria do direito (a relação entre valores e obrigações) teria produzido consequências como a desordenada proliferação de direitos que, segundo sua análise, caracteriza a expansão dos direitos humanos. Para ele, essa retórica dominante reforça a visão de que os direitos humanos são direitos absolutos, mas despreza o fato de que a sua aplicação depende da sensibilidade às diversidades culturais. Seu raciocínio alerta ainda para o fato de que o fortalecimento irrefletido das condições de aplicação dos direitos humanos pode causar danos graves aos Estados que vierem a sofrer intervenções, caso não existam instituições imparciais, eficientes e confiáveis para conduzir esse processo (RAZ, 2010b, p. 47).

$\mathrm{Na}$ sua reconstrução política dos direitos humanos Raz evidencia a falência das teorias tradicionais para lidar com as complexidades envolvidas na reflexão sobre os direitos humanos atualmente, sobretudo das teorias de natureza ética, como em Alan Gewirth e James Griffin. Para Raz (2010a, p. 322), uma doutrina ética dos direitos humanos estabelece padrões por meio dos quais as práticas de direitos humanos devem ser julgadas, além de indicar o que são e quais são os direitos humanos que cada um de nós, de fato, possui. Raz define três razões pelas quais as doutrinas tradicionais de ética normativa falham ao explicar e justificar os direitos humanos: a) elas não entendem a relação entre valores e direitos; b) elas se excedem, tentando justificar a existência de muitos direitos; e c) falham ao não conseguir lançar luzes ou criticar práticas de direitos humanos. Raz (2010a, p. 324) entende que autores como Gewirth, Griffin e Waldron passam da doutrina ética para os direitos humanos confundindo, assim, valores morais e necessidades básicas da natureza humana com o consequente e necessário reconhecimento de que são direitos, sem, contudo, explicar essa correlação. James Griffin, por exemplo, afirma Raz, defende como necessária uma derivação de direitos a partir da noção de que certos bens ou valores são valiosos para as pessoas porque corresponderiam à defesa de aspectos essenciais de sua personalidade e do exercício primordial da liberdade, o que importaria em defesa especial desses direitos. Mas, insiste Raz, não basta que algo seja especial para as pessoas para merecer especial proteção diante de outras necessidades - o amor dos filhos pelos pais pode ser importante, mas os pais não têm "direito" a esse amor, exemplifica Raz (2010a, p. 325). Raz julga razoável a proposta feita por Griffin para definir os direitos humanos como aqueles direitos que defendem a capacidade dos seres humanos para o agir moral. Mas Griffin, afirma Raz, ultrapassa essa linha e estende os fundamentos dos direitos humanos para além da capacidade de ação intencional, incluindo condições necessárias para que a ação obtenha sucesso direito à educação, informação, recursos, oportunidades e etc. -, até o ponto em que Griffin (2010a, p. 326) concebe um "mínimo", o qual aparece como recurso metodológico para salvar o argumento de imprecisão ou de demasiada extensão do número desses direitos. $O$ problema com as teorias tradicionais, argumenta Raz, é que elas definem os direitos humanos como direitos morais sem, contudo, estabelecer critérios para o reconhecimento de quais direitos mínimos servem como padrão 
universal. Por esse motivo, para Raz (2010a, p. 328) uma teoria dos direitos humanos deve ter por objetivo a) estabelecer os critérios (features) essenciais que as práticas contemporâneas de direitos humanos atribuem aos direitos reconhecidos como tais; e b) identificar os padrões morais que qualificam qualquer coisa que deva ser reconhecida como tal.

Para corrigir esses erros, Raz (1986, p. 176) propõe a extensão de sua teoria do direito aos direitos humanos com algumas reformulações, recuperando a premissa de Morality of Freedom, segundo a qual "os direitos não são mais do que fundamentos (grounds) para deveres." Inicialmente, é preciso reconhecer que quatro truísmos definem a natureza específica dos direitos no universo moral: 1. o objeto dos direitos é algo de valor; 2. ter um direito é algo de valor para o titular desse direito; 3. o direito de uma pessoa gera deveres para as outras (para poder assegurá-lo); 4. o direito é protegido por deveres - mas seu titular pode renunciar/suspender esse direito; (ou seja, os titulares, they have a say in their enforcement) (RAZ, 2010b, p. 41). Assim, somente existem direitos quando existem obrigações correspondentes a esses direitos, e somente se pode afirmar que temos um direito se o valor de o possuir, ou nossa necessidade de possuí-lo, for capaz de impor deveres aos outros (RAZ, 2010 b, p. 36). Ao contrário das outras coisas que possuem valor para seus portadores, o direito é do tipo de coisa que, além de possuir um valor, garante e vincula outros que são obrigados a respeita-lo ou são de alguma forma forçados a isso. Em direitos humanos, prossegue Raz, o problema teórico fundamental é o hábito de justificar a existência de um direito apenas em razão da importância (valor) que ele possui para o portador, tornando-se necessário demonstrar por que os outros deveriam se sujeitar a cumprir deveres com relação a esse portador (RAZ, 2010b, p. 37).

Nesse sentido, para Raz (2010b, p. 41), o papel exercido pelos direitos individuais na reflexão é preponderante, porque assumem não apenas a função de direitos morais que a legislação deve reconhecer e respeitar, mas também a função de "direitos morais de um tipo especial", porque eles "expressam a visão de que toda vida humana é valiosa incondicionalmente." É a soma da importância excepcional atribuída ao conjunto de direitos individuais e a possibilidade real universalização que define os direitos humanos. Raz explica que cada época e cada comunidade pode escolher prioridades (direitos especiais), e essas prioridades podem variar bastante de modo que não é correto falar em verdades absolutas sobre direitos e valores que devam ser universalizados, necessariamente - nem mesmo sua defesa dos direitos individuais pode gozar dessa preferência. Mas, por razões pragmáticas, Raz argumenta que devemos destacar do extenso arcabouço internacional aqueles direitos que já são sincronicamente reconhecidos como universais e cuja violação cause, reconhecidamente, o maior impacto na ordem soberana violadora desses direitos (RAZ, 2010b, p. 42). Desse modo, não é a natureza dos direitos que funda a universalidade, como pressuposto por Nickel (2014), Griffin (2008) ou mesmo por Beitz (2009), mas a reconhecida universalidade que funda a categoria dos direitos humanos. Mas ainda resta um elemento: para Raz, somente podem ser definidos como direitos humanos os direitos efetivamente reconhecidos como universais na prática internacional e cuja violação enseje a quebra da soberania estatal. 
Definindo os direitos humanos dessa forma Raz pretende corrigir os erros de muitos ativistas que se preocupam em apontar a importância de um direito ou seu objeto para seus titulares; e se negam a vincular as outras pessoas ao dever de garantir e respeitar aquele direito. Por isso, nem todos os direitos morais são direitos humanos, somente o são aqueles enforced by law, ou seja, aqueles que obrigam ao seu cumprimento. Além disso, são necessárias instituições fortes, justas e confiáveis para conduzir a aplicação desses direitos; se o enforcement é impossível então não se deve exigi-lo (RAZ, 2010b, p. 44).

Outra dificuldade apontada por Raz é o fato de que certos direitos humanos possuem um conteúdo impreciso demais para garantir sua aplicação. Mas com relação a esse ponto penso que Raz extrapola a discussão com o uso de exemplos um tanto pífios (direito à mais elevada condição saúde, à educação de qualidade e etc.) parecendo-me mais interessado em reforçar a tese de que somente direitos individuais podem ser universalizados do que em provar que direitos sociais, em geral, são tão imprecisos que jamais poderão ser. Sobre esse ponto lembro que em muitos países alguns direitos individuais básicos são de muito mais difícil aplicação do que alguns direitos sociais mais complexos. É o caso de estados economicamente fortes, mas refratários à defesa de certas liberdades individuais - liberdade de expressão, de crença, de associação, de participação política e etc. - como a China, a Arábia Saudita, Jordânia e Cuba. Para esses países qualquer discussão econômica sobre o avanço dos padrões de saúde e educação é mais tolerável/adaptável do que uma discussão sobre implantar a liberdade partidária ou a liberdade de expressão política, p. ex.

De todo modo, para Raz (2010a, p. 336) uma justificação racional dos direitos humanos depende do reconhecimento da excepcionalidade dos direitos individuais, da obrigação estabelecida para o Estado de respeitá-los e promovê-los, e de que as imunidades da soberania não possam ser utilizadas para bloquear a interferência internacional em caso de violações graves desses direitos.

De inspiração rawlsiana, essa compreensão dos direitos humanos como limitações moralmente justificáveis para a soberania estatal foi adaptada por Raz (2010a, p. 329), não sem críticas. Em sua visão, Rawls foi longe demais ao estabelecer certa confusão entre limitações à soberania e o exercício da autoridade legítima. Para Raz, a preocupação de Rawls com as condições sociais de cooperação em Uma teoria da justiça são relevantes para os objetivos da autoridade do Estado, mas não podem determinar os limites da soberania na forma sugerida em $O$ direito dos povos. Isso porque as condições de legitimidade interna podem sofrer com uma diversidade de problemas graves - corrupção, por exemplo - que não autorizam a intervenção externa - "nem todos os erros constituem tão graves violações de direitos." (RAZ, 2010a, p. 332).

Para Raz, os direitos individuais são direitos humanos se, e somente se, invalidam argumentos contra a interferência externa nos assuntos do estado. E as principais consequências dessa concepção política dos direitos humanos é que não precisam de uma abordagem fundacional, normativa ou substantiva. 


\section{Conclusão}

funcionalismo político em direitos humanos propõe uma mudança de abordagem da discussão sobre o estabelecimento de critérios para definir quais direitos são ou não direitos humanos - e porquê. Evitando definir direitos em razão das necessidades básicas da natureza humana ou mesmo a partir de valores essenciais que a humanidade de todas as épocas deveria proteger os defensores do funcionalismo político cobram a importância de refletir sobre as práticas legais e institucionais em direitos humanos.

Pressionado pelo realismo internacionalista John Rawls impôs limites aos amplos direitos liberais oriundos de Uma teoria da justiça para afirmar uma curta lista de direitos humanos factível perante uma comunidade global e pluralista. Rawls definiu ainda que a obediência aos direitos humanos deveria ser obrigatória para todos os povos interessados em ingressar na ordem internacional, e que o descumprimento desses direitos autorizaria a intervenção na soberania do Estado. Dworkin, ampliou a função dos direitos humanos para o estabelecimento das próprias condições de legitimidade política da socialização, mas afirmou que a especificidade desses direitos somente poderia ser esclarecida circunstancialmente - contrariando a posição dos normativistas clássicos e dos naturalistas. Charles Beitz defende que os direitos humanos assumam o papel de standards civilizatórios; mas Joseph Raz é o mais enfático defensor da posição segundo a qual somente se deve definir os direitos humanos em razão da importância e da função que certos direitos assumem ao suspender as imunidades da soberania estatal em casos de graves violações.

No conjunto, o funcionalismo político afirma seus méritos por escapar ao idealismo das teorias tradicionais (ortodox view), tomando por ponto de partida o realismo político vigente na ordem global. Além disso, seus defensores argumentam que podem definir do modo mais preciso quais direitos são direitos humanos e que essa precisão decorre do sentido prático de sua forma de avaliar o tema. Graças a esse sentido prático, os defensores do funcionalismo político insistem que sua visão dá conta do maior problema relativo à definição dos direitos humanos: ela evitaria a carência de eficácia tão comum do modelo de listas de direitos, já que toma por direitos humanos aqueles direitos que já são admitidos - ou com maior propensão a serem admitidos - pela comunidade internacional. Por fim, seguindo esse caminho aberto por Rawls, os funcionalistas políticos argumentam utilizar menos o discurso intervencionista, dado que em sua visão os motivos para isso são bem menos amplos.

Apesar do valor de muitas contribuições do funcionalismo político para o debate atual todos os seus críticos apontam que o minimalismo jurídico decorrente de suas posições é inaceitável, sobretudo diante da realidade prática - e do amplo conjunto normativo em vigor tanto no sistema ONU, quanto em sistemas regionais como o da União Europeia e das Américas. Por essa crítica, o minimalismo conforme proposto por Rawls e seguido por Dworkin e Raz também não atingiria a finalidade de proteger, de fato, as condições básicas de humanidade das pessoas em qualquer lugar. 
Dentre outros motivos, sobretudo porque submeteria a linguagem dos direitos morais inerentes ao ser humano à linguagem dos interesses políticos de Estados e grupos nacionais, transformando as melhores expectativas sobre esses direitos em objeto de negociação conjuntural. $\bigcirc$ próprio internacionalismo marcante da reflexão funcionalista manteria o acesso aos direitos humanos muito longe das pessoas comuns. Isso porque na visão de Rawls e Raz apenas seriam alvo de proteção internacional pessoas ou grupos vítimas de violações muito graves para justificar intervenções na soberania do Estado violador, o que somente é justificável em casos muito raros.

Restam ainda as críticas substantivistas. Griffin (2010a, p. 343) acusa Dworkin de não oferecer o que deveria para uma análise dos direitos humanos: os critérios para afirmar quais direitos humanos de fato existem e o que são esses direitos. Griffin afirma ainda que ao argumentar que os direitos humanos são "trunfos" contra os excessos do governo Dworkin falha por não distinguir os direitos humanos de outros trunfos da mesma natureza - a justiça, a equidade e etc. -, e por não atribuir elementos substantivos que nos permitam compreender melhor o conteúdo desses direitos políticos, tornando-os muito abstratos (GRIFFIN, 2010a, p. 341). Quanto a Rawls, Griffin não entende porque ele coloca o selo de "direitos humanos" em sua curta lista de direitos em Law of Peoples. "Não há razões suficientes para isso", argumenta Griffin, assim como Rawls também não nos diz porque sua lista é "urgente" e reúne direitos de uma "classe especial", deixando outros direitos muito semelhantes de fora (GRIFFIN, 2010a, p. 342). Griffin afirma ainda que os direitos humanos não servem apenas para evitar guerras injustas, reforçando o argumento contra a internacionalização desmedida da reflexão sobre os direitos humanos, como se eles não pudessem servir para a ordem jurídica interna. Para Griffin (2010a, p. 343), Rawls, como Dworkin, não definem bem o conteúdo de "minimum wellfare", nem estabelecem em que nível a negação desse minimum deve justificar intervenções, rebatendo as afirmações dos funcionalistas em geral contra a alegada imprecisão das teorias tradicionais para definir os direitos humanos.

Reforçando a crítica contra o internacionalismo do funcionalismo político de Raz e Rawls Jeremy Waldron argumenta que não é inevitável separar direitos humanos e os direitos constitucionais para tomar essa relação como base da distinção entre a ordem jurídica interna e a ordem jurídica externa - sobretudo para defender que a existência dos direitos humanos se fundamenta na possibilidade de derrogar a soberania. Para Waldron (2013, p. 15), os direitos humanos propõem a adaptação da ordem jurídica interna a uma série de normas e valores que podem e devem coexistir com a ordem internacional; aos problemas dessa adaptação correspondem vários tipos de reação, e quase nenhuma delas são intervenções armadas.

Raz respondeu a Waldron afirmando que sugeriu como elemento identificador das práticas de direitos humanos o papel que elas exercem nas relações internacionais por dois motivos: primeiro, porque as relações internacionais sofreram modificações mais radicais com os direitos humanos do que as relações entre indivíduos, corporações e os Estados nos territórios em que se localizam; em segundo lugar, porque nas relações internacionais esses direitos simplesmente inexistiam, e o seu 
crescimento se tornou um fenômeno único (RAZ, 2013, p. 5). Em termos teóricos, Raz admite que é possível conceber direitos possuídos por seres humanos pelo simples fato de serem humanos, mas afirma também que os valores que lhes dão origem, assim como a aplicabilidade desses direitos dependem de circunstâncias históricas particulares, e que nem mesmo eventuais teorias verdadeiras de direitos humanos poderiam servir de padrão para avaliar as práticas em direitos humanos (RAZ, 2013, p. 3).

Penso que a crítica de Raz exacerba a visão internacionalista de Rawls até o ponto em que a transforma em uma verdadeira teoria, muito restritiva, dos direitos humanos (distinta de sua teoria do direito) - algo que ele insiste em negar, mas que sua forma de argumentar confirma, reiteradamente.

O debate sobre a natureza dos direitos humanos continua sendo relevante tanto para racionalizar os critérios por meio dos quais estabelecemos valores prioritários (grounds) para esses direitos, quanto para decidir quais obrigações devem ser cumpridas por quais atores (duty-beares) (LIAO; ETINSON, 2012, p. 352).

É fato que o modelo de listas de direitos permitiu o aumento da categoria dos direitos humanos até o ponto em que não se pode afirmar acerca de muitos deles que são completamente eficazes. Mas esse não parece ser um problema tão fundamental, em termos teóricos, afinal, em toda ordem jurídica interna existem problemas semelhantes com várias classes de direitos. Esse argumento devolve aos teóricos ortodoxos ou tradicionais a voz para continuar em busca de padrões justificáveis de decisão sobre uma lista de direitos mais coerente, enquanto os funcionalistas políticos podem contribuir para a consolidação dos direitos humanos com as pesquisas que mostram o melhor caminho para tornar esses direitos mais eficazes, em escala global.

\section{Referências}

BAYNES, Kenneth. Toward a political conception of human rights. Philosophy \& Social Criticism, v. 35, n. 4, p. 371-390, 2009.

BEITZ, Charles. The idea of human rights. Oxford: Oxford University Press, 2009.

BEITZ, Charles. Human dignity in the theory of human rights: nothing but a phrase? Wiley Periodicals, Inc. Philosophy \& Public Affairs, v. 41, n. 3, p. 250-290, 2013.

BESSON, Samantha; TASIOULAS, John (ed.). The Philosophy of International Law. Oxford: Oxford University Press, 2010.

CLARK, Megan. Reasoned agreement versus practical reasonableness: grounding human rights in Maritain And Rawls. The Heythrop Journal, v. LIII, p. 637-648, 2012.

COHEN, Joshua. Minimalism about human rights: the most we can hope for? The Journal of Political Philosophy, v. 12, n. 2, 2004. 
CRUFT, Rowan; LIAO, S. Matthew; RENZO, Massimo. Philosophical foundations of human rights. Oxford: Oxford University Press, 2015.

DONNELLY, Jack. Universal human rights in theory and practice. Ithaca: Cornell University Press, 2003.

DONNELLY, Jack. The relative universality of human rights. Human Rights Quarterly, v. 29, n. 2, p. 281-306, May 2007.

DWORKIN, Ronald. A raposa e o porco-espinho - justiça e valor. São Paulo: Martins Fontes, 2014.

FREEMAN, Michael. Human rights - an interdisciplinary approach. Cambridge: Polity Press, 2010.

GEWIRTH, Alan. Human rights: essays on justification and applications. Chicago: The University of Chicago Press, 1982.

GEWIRTH, Alan. Moral foundations of civil rights law. Journal of Law and Religion, v. 5, n. 1, p. 125-147, 1987.

GEWIRTH, Alan. The basis and content of human rights. Nomos, v. 23, p. 119-147, 1981.

GLENDON, Mary Ann. A world made new - Eleanor Roosevelt and the universal declaration of human rights. New York: Random House, 2001.

GOODALE, Mark. The myth of universality: the UNESCO "philosophers' committee" and the making of human rights. Law \& Social Inquiry, v. 43, n. 3, 2017. DOI: 10.1111/1si.12343.

GRIFFIN, James. On human rights. Oxford: Oxford University Press, 2008.

GRIFFIN, James. Human rights and the autonomy of international law. In: BESSON, S.; TASIOULAS, J. (ed.). The Philosophy of International Law. Oxford: Oxford University Press, 2010a. p. 339357.

GRIFFIN, James. Human rights: questions of aim and approach. Ethics, v. 120, July 2010 b.

IGNATIEFF, Michael. Human rights as politics - human rights as idolatry. The Tanner Lectures on Human Values. Princeton: Princeton University Press, 2000.

LANGLOIS, Anthony J. Human rights without democracy? A critique of the separationist thesis. Human Rights Quarterly, v. 25, n. 4, p. 990-1019, Nov. 2003.

LIAO, S. Matthew; ETINSON, Adam. Political and naturalistic conceptions of human rights: a false polemic? Journal of Moral Philosophy, v. 9, p. 327-352, 2012.

MACLEOD, Alistair M. Rawls's narrow doctrine of human rights. In: MARTIN, Rex; REIDY, David A. (ed.). Rawls's law of peoples - a realistic utopia? Malden, MA: Blackwell Publishing, 2006.

NICKEL, James W. What future for human rights? Ethics \& International Affairs, v. 28, n. 2, p. 213223, 2014. 
NICKEL, James. Are human rights mainly implemented through intervention? In: MARTIN, Rex; REIDY, David A. (ed.). Rawls's law of peoples - a realistic utopia? Malden, MA: Blackwell Publishing, 2006.

POGGE, Thomas. Do Rawls's two theories of justice fit together? In: MARTIN, Rex; REIDY, David A. (ed.). Rawls's law of peoples - a realistic utopia? Malden, MA: Blackwell Publishing, 2006.

RAWLS, John. O direito dos povos. São Paulo: Martins Fontes, 2001.

RAZ, Joseph. Human rights in the emerging world order. Transnational Legal Theory, v. 1, p. 31-47, 2010a.

RAZ, Joseph. Human rights without foundations. In: BESSON, S.; TASIOULAS, J. (ed.). The philosophy of international law. Oxford: Oxford University Press, 2010b. p. 321, 330-333.

RAZ, Joseph. On Waldron's critique of Raz on human rights. Public Law \& Legal Theory Working Paper Group - Legal Research Paper Series. Paper No 80/2013, Aug. 2013.

RAZ, Joseph. The morality of freedom. Oxford: Oxford University Press, 1986.

SHUE, H. Basic rights: subsistence, affluence, and U.S. foreign policy. 2. ed. Princeton: Princeton University Press, 1996.

TASIOULAS, John. From Utopia to Kazanistan: John Rawls and the Law of Peoples. Oxford Journal of Legal Studies, v. 22, p. 367-396, 2002.

TASIOULAS, John. Towards a philosophy of human rights. Current Legal Problems, v. 65, n. 1, p. 1-30, 1 January 2012.

UNESCO. Human rights - comments and interpretations. Paris: UNESCO/PHS/3, 25 July 1948.

VOICE, P. Rawls explained: from Fairness to Utopia. Chicago: Open Court Press, 2011.

WALDRON, Jeremy. Human rights: a critique of the Raz/Rawls approach. New York University Public Law and Legal Theory, Working Papers. Paper 405, 2013.

WALDRON, Jeremy. Is dignity the foundation of human rights? In: CRUFT, Rowan; LIAO, S. Matthew; RENZO, Massimo. Philosophical foundations of human rights. Oxford: Oxford University Press, 2015. p. 117-138. 
